\title{
Impuestos municipales, precios y salarios reales en la Castilla del siglo XVII: el caso de Madrid*
}

\author{
José Ignacio Andrés Ucendo \\ Universidad del País Vasco \\ Ramón Lanza García \\ Universidad Autónoma de Madrid
}

RESUMEN: Este artículo analiza el papel de los impuestos municipales y en qué medida estos tributos hicieron subir los precios en torno a un 20\% y bajar los salarios reales entre un 15 y un 20\% en Madrid durante los años que median entre 1596 y 1700, resultados que bien pueden considerarse representativos de una tendencia general en las ciudades castellanas del siglo XVII. De un modo más general, los autores citados, utilizando documentación del Archivo Histórico Nacional, del Archivo General de Palacio y del Archivo General de Simancas, afirman que la suma del pago de los impuestos reales y de los impuestos municipales, es decir, de la fiscalidad en su conjunto, tuvo una decisiva influencia en la decadencia de la hasta entonces floreciente red urbana del reino castellano, pues, entre otras cosas, redujo la competitividad de las manufacturas que se fabricaban en dichas ciudades. Cualquier estudio de los impuestos cobrados por la villa durante este período conduce al análisis de las estrechas relaciones financieras entre la Corona y su capital. Para reunir la

* Este trabajo se ha realizado gracias al Proyecto de Investigación del MEC «Fisco y mercado: fiscalidad, derechos de propiedad y cambio institucional en la España del siglo XVII», HAR2008-05425. Los autores desean expresar su agradecimiento a Luis María Bilbao, José Ignacio Fortea, Juan Eloy Gelabert y Enrique Llopis por los comentarios a una versión anterior de este trabajo, que fue presentada en la sesión Q6, «Urban Fiscal Systems and Economic Growth in Europe, 15th-18th Centuries» del XVth International Economic History Congress, Utrecht, 2009. Asimismo nos complace expresar nuestro más sincero agradecimiento al personal del Archivo General de Simancas (AGS), Archivo General de Palacio (AGP) y Archivo Histórico Nacional (AHN) por las facilidades que nos han ofrecido para la realización de este trabajo. 
suma que Madrid otorgó a la Corona mediante donativos, la ciudad pidió prestadas estas cantidades. A cambio, la Real Hacienda transfirió a Madrid la mayor parte de los impuestos reales que se cobraban en la villa y su distrito fiscal, permitiendo también que Madrid introdujera nuevos impuestos municipales para pagar los intereses y amortizar el principal de las sumas tomadas en préstamo.

\section{Palabras Clave: Madrid; Siglo XVII; Fiscalidad; Precios; Salarios; Haciendas municipales.}

\section{Municipal Taxes, Prices and Real Wages in XVII ${ }^{\text {th }}$ century Castile: The Case of Ma- drid}

ABSTRACT: This essay analyzes the influence of the indirect taxes levied by Madrid on price and wage levels in the Castilian capital and shows that at the end of the seventeenth century indirect taxes raised price levels around $15-20 \%$, reducing real wages to the same measure. The Madrilian case suggests that indirect taxation should have exerted a strong influence in the growing problems of the Castilian cities during the seventeenth century crisis, damaging the competitiveness of the urban industries. The study of Madrid's case leds to the consideration of the close financial relationships between the Crown and its capital city during the Seventeenth Century. The Crown asked Madrid many «donativos», especially after 1653, and to raise the sums raised in such «donativos» Madrid developed its debt, issuing bonds or «censos». To pay the interest of such «censos» the Crown transferred Madrid the control of most part of the «servicios de millones» collected in the city and its fiscal district, but as this was not enough the Royal Treasury also allowed Madrid to create new municipal taxes.

KEY WORDS: Madrid; Seventeenth Century; Taxation; Prices; Wages; Municipal Treasuries.

\section{INTRODUCCIÓN}

La existencia de una red urbana es generalmente considerada como una de las condiciones de cualquier proceso de crecimiento económico. La división del trabajo ente el campo y la ciudad crea un ambiente propicio para el avance de los mercados, conduciendo a mayores niveles de productividad y a un crecimiento económico sostenido. Visto desde este punto de vista, entonces, podría decirse que la España del siglo XVI estaba bien situada en la carrera del desarrollo económico gracias a la presencia de una de las redes urbanas más densas del continente, cuya importancia sólo era superada por las del norte de Italia, los Países Bajos y Portugal ${ }^{1}$.

1 WRIGLEY, 2004; 58. 
Sin embargo, la historia de la economía española y, en particular, castellana a lo largo del siglo XVII estuvo presidida por la crisis y las dificultades, siendo la decadencia de la hasta entonces floreciente red urbana del reino uno de los aspectos más reseñados de todo el proceso.

Siempre se ha considerado que la fiscalidad tuvo un relieve particular entre las causas que condujeron a la crisis urbana del período. La Corona castellana recaudaba sus ingresos fiscales a través de un sistema de impuestos indirectos sobre la venta y el consumo de una amplia gama de productos, aunque debe resaltarse que el peso de tales tributos recaía principalmente sobre un número reducido de productos de consumo masivo, como el pescado, el aceite de oliva y, en especial, la carne y el vino, y que el pan, el producto más importante con mucho, estaba prácticamente exento de tributación².

Este sistema afectó a las ciudades del reino de dos formas que ayudan a explicar sus negativos efectos sobre las economías urbanas del país. En primer lugar, dados los limitados avances de la economía de mercado en la mayor parte del mundo rural, el peso de este tipo de tributación tendió a caer de forma desproporcionada sobre las ciudades y a esto debe añadirse, en segundo, que de acuerdo con los testimonios de los arbitristas la imposición indirecta elevó los niveles de precios y salarios, reduciendo la competitividad de las manufacturas castellanas ${ }^{3}$.

Este último aspecto ha atraído el interés de los investigadores. Al menos desde las últimas décadas del siglo XVI, si no desde antes, era comúnmente admitido que los impuestos indirectos tendían a aumentar los niveles de precios y que esto a su vez repercutió en el alza de los salarios, aunque del testimonio de arbitristas tan conocidos como Sancho de Moncada se desprende que tal subida no compensó las alzas de los niveles de precios provocadas por los impuestos indirectos, algo que debió de haber deprimido los niveles de consumo de productos básicos entre los sectores más humildes de las ciudades castellanas, reduciendo los niveles de vida de la mayor parte de la población urbana del país 4 .

La visión arbitrista sobre las relaciones entre la tributación indirecta, los niveles de precios y salarios y el deterioro en los niveles de vida fue adoptada por los ilustrados españoles, que a su vez la transmitieron a los tratadistas liberales del siglo XIX. Esta teoría todavía es muy influyente, y puede afirmarse que ha condicionado nuestra interpretación de las dificultades sufridas por las ciudades castellanas de la época 5 .

2 Sobre la fiscalidad castellana del XVII, DOMÍNGUEZ ORTIZ, 1960 y ARTOLA, 1980.

3 RUIZ MARTÍN, 1978: 37-47; GARCÍA SANZ, (Madrid, 1991): 15-24. GELABERT, 1997: 348-50. MARCOS MARTÍN, 2000: 522-23. YUN, 2002: 80-81 y 105.

4 MONCADA, 1974: 187-188.

5 A modo de ejemplo, se pueden leer las influyentes obras de UZTÁRIZ, 1968: 21-22 y COLMEIRO, 1986: 371. 
La investigación actual ha incluido nuevos elementos que ayudan a matizar la teoría más tradicional. Aunque su importancia ha sido por lo general subestimada, al menos desde las últimas décadas del siglo XVII, sus contemporáneos resaltaban la influencia de los impuestos municipales recaudados por las ciudades castellanas en el alza de los niveles de precios. Las ciudades del país obtenían sus ingresos de dos fuentes principales: la explotación de los patrimonios comunales y los impuestos. Después de la investigación de las últimas décadas, parece claro que la importancia de los impuestos municipales tendió a crecer a lo largo del siglo XVII. Siguiendo el ejemplo de la Corona, las ciudades castellanas tendieron a recurrir a los impuestos indirectos sobre el consumo de productos que ya estaban siendo gravados por otros impuestos reales, por lo que hay buenas razones para sugerir que la política fiscal seguida por las ciudades castellanas tuvo que reforzar las alzas de precios y salarios y el descenso en los niveles de vida provocados por los tributos reales, lo que ayuda a comprender el interés sobre las consecuencias de la proliferación de impuestos municipales sobre el vinagre, el aceite de oliva y, en especial, la carne y el vino que manifestó en las primeras décadas del siglo XVIII la nueva dinastía de los Borbones ${ }^{6}$.

La investigación más reciente ha comenzado a analizar el papel de los impuestos municipales. El objetivo de las líneas que siguen es estudiar en qué medida estos tributos afectaron los niveles de precios y salarios en las ciudades castellanas del Seiscientos a través de un estudio centrado en la capital del país, Madrid, durante los años que median entre 1596 y 1700.

La primera parte del trabajo describe el sistema fiscal creado por la capital a lo largo del siglo XVII. Cualquier estudio de los impuestos cobrados por la villa durante este período conduce al análisis de las estrechas relaciones financieras entre la Corona y su capital. De acuerdo con nuestros cálculos, entre 1653 y 1679 Madrid otorgó a la Corona cerca de 17 millones de ducados en varios donativos. Para reunir esta suma la capital recurrió al endeudamiento municipal. La ciudad pidió prestadas las cantidades que ofrecía a la Corona en los donativos y a cambio la Real Hacienda transfirió a Madrid la mayor parte de los impuestos reales que se cobraban en la villa y su distrito fiscal, permitiendo también que Madrid introdujera nuevos impuestos municipales para pagar los intereses y amortizar el principal de las sumas tomadas en préstamo, algo que la ciudad usó para introducir impuestos sobre el carbón vegetal, el azúcar y, sobre todo, la carne y el vino. Como resultado de todo lo anterior, los ingresos fiscales de la ciudad crecieron de 0,4 millones de ducados en 1654 a

6 Sobre los impuestos municipales en la Castilla del siglo XVII, MARTÍNEZ RUIZ, 1992. GUTIÉRREZ ALONSO, 1989: 334-390. REY CASTELAO, (Santiago de Compostela, 2004): 215-252. Una visión de conjunto sobre los problemas de los patrimonios municipales, FORTEA PÉREZ, 1999: 83-85. 
1,7 millones en 1679, muy por encima del alza del nivel de precios, que en el mismo período creció de un índice 100 en 1654 a 167 en 1679.

La forma en que los impuestos indirectos recaudados por la Corona y el municipio afectaron a los precios y a los salarios reales en la capital es mostrada en el segundo y tercer apartados de este trabajo. La segunda parte presenta el índice de precios y salarios en Madrid entre 1596 y 1700. Para calcular el índice de precios hemos recopilado los precios del pan, el vino ordinario, la libra de carnero, el carbón vegetal y el paño pardo, y para el resto de los productos del índice hemos recurrido a los datos de Hamilton. En cuanto a los salarios, éstos corresponden a los jornales obtenidos por los peones de albañil que trabajaban en las obras del Alcázar Real y del Real Colegio de Santa Isabel, por lo que pueden considerarse representativos de la trayectoria de esta variable entre los trabajadores y miembros de los grupos más humildes de la sociedad madrileña de la época.

Tras reconstruir el índice de precios y el salario nominal hemos calculado la evolución del salario real de un peón de albañil en Madrid entre 1596 y 1700. Después de una importante subida entre 1596 y las primeras décadas del siglo XVII, los salarios reales tendieron a caer en Madrid, reduciéndose alrededor de un 50\% respecto de los niveles más elevados de 1610-20 en los peores años de la inflación del vellón. Aunque tras las reformas monetarias y fiscales de los años 80 se produjo una recuperación, ésta no bastó para compensar el terreno perdido en las décadas anteriores. Justamente la tercera parte del trabajo analiza la responsabilidad de los impuestos reales y, en especial, municipales en esta trayectoria.

De acuerdo con nuestras estimaciones, la importancia de la fiscalidad sobre los niveles de precios y los salarios reales subió continuamente a lo largo del período, culminando en las últimas décadas del siglo. Al final del siglo XVII los impuestos elevaron los niveles de precios en la capital en alrededor de un $20 \%$. Como era previsible, esto no dejó de afectar a los salarios reales de los albañiles madrileños que, en ausencia de impuestos indirectos, habrían sido entre un 15-20\% superiores en 1665 y 1700, siendo digno de mención que a fines de siglo la influencia de los tributos municipales sobre los precios y salarios reales parece haber sido mayor que la de los impuestos reales. Podría alegarse que el supuesto sobre el que descansa este ejercicio, la ausencia de impuestos indirectos en el Madrid del siglo XVII, es irreal. Después de todo, debe reconocerse que incluso en el mejor caso tanto la Corona como la villa tendrían que haber cobrado algún tipo de impuesto para obtener los ingresos con los que financiar sus funciones más importantes $\mathrm{y}$, teniendo en cuenta las características de la sociedad castellana de la época, parece más que probable que tal impuesto hubiese sido indirecto. Al mismo tiempo, también parece claro que en ausencia de tributos indirectos el índice de salarios 
nominales usado para calcular nuestro índice de salarios reales hubiera evolucionado de modo distinto. Sin embargo, estas observaciones no debieran ocultar que el interés del ejercicio llevado a cabo en el tercer apartado reside en que ofrece una medida de la influencia de la tributación indirecta en los niveles de precios y salarios madrileños, enfatizando el papel de los tributos indirectos cobrados por el municipio, que ha tendido a ser tradicionalmente ignorado por los historiadores.

\section{HACIENDA REAL Y HACIENDA MUNICIPAL}

A lo largo de la Edad Moderna las ciudades castellanas dependieron de sus patrimonios comunales y de los tributos para obtener sus ingresos, aunque la importancia relativa de cada una de estas fuentes de ingresos variaba de acuerdo con las circunstancias locales. Tras su reconquista, algunas ciudades como Sevilla habían recibido un rentable patrimonio comunal, de cuya explotación obtuvieron una parte sustancial de sus ingresos ordinarios, algo que no sucedía en otros casos, como Madrid, donde este tipo de propiedad era mucho menos importante, lo que obligó a la capital a confiar en los tributos para obtener la mayor parte de sus ingresos ${ }^{7}$.

Como resultaba habitual en la mayoría de las ciudades castellanas, los impuestos cobrados por las autoridades municipales eran indirectos y gravaban productos como el pescado, aceite, carbón vegetal, y en especial la carne y el vino $^{8}$. En 1580 Madrid había introducido un grupo de recargos sobre el consumo del vino, carnero, carne de cerdo, cordero y jabón, llamados «Sisas Ordinarias», y a fin de obtener los ingresos con los que financiar los crecientes gastos causados por el definitivo establecimiento de la Corte en la capital en 1606, en el primer tercio del siglo se introdujo un conjunto de impuestos que elevaron los ingresos de la hacienda municipal madrileña de poco más de 25 millones de maravedíes en 1606 a 113 millones en $1631^{9}$.

Aunque la creación de impuestos no se interrumpió durante la tercera y cuarta décadas del siglo, en que las autoridades municipales introdujeron

7 MARTÍNEZ RUIZ, 1992 y ANDRÉS UCENDO, (Madrid, 2006): 45.

8 Para el sistema fiscal madrileño del siglo XVII, vid. HOZ GARCÍA, (Madrid, 1988): págs. 371-386 y también ANDRÉS UCENDO, 30/3 (Roma, 2001): 67-80.

9 Estos impuestos fueron las «Sisas del Cuarto de Palacio», sobre la vaca, carnero y pescado (en 1608); las «Sisas de la Sexta Parte», cobradas desde 1611 sobre el consumo del vino, cera, jabón y azúcar; la «Sisa del Vino de la Plaza», cobrada sobre el consumo del vino desde 1618 y la «Sisa del Carnero de Fuentes» y la «Sisa del Vino de la Cárcel» sobre el consumo de vino y carnero desde 1621 y 1630 respectivamente. Véase HOZ GARCÍA, (Madrid, 1988). Sobre el valor de los impuestos en Madrid, ANDRÉS UCENDO, 30/3 (Roma, 2001): 66-68. 
otros cuatro impuestos nuevos, los ingresos de Madrid se estabilizaron hasta 1653 alrededor de los niveles alcanzados en 1631. En noviembre de 1653 Madrid otorgó a la Corona un donativo de 220.000 ducados y entonces comenzó una nueva fase ${ }^{10}$.

Según se ha citado más arriba, entre 1653 y 1679 Madrid otorgó a la Corona casi 17 millones de ducados en varios donativos y para obtener las sumas ofrecidas en cada donativo la ciudad expandió su deuda municipal. Madrid pedía prestadas las sumas concedidas a la Corona y con la idea de proporcionar a su capital una fuente de ingresos segura para pagar los intereses y amortizar los principales de las sumas prestadas, la Corona transfirió a Madrid la mayor parte de los impuestos reales cobrados en la capital y su distrito fiscal, permitiendo al mismo tiempo que la villa introdujera nuevos impuestos municipales ${ }^{11}$.

Esto causó una notable subida de los ingresos municipales, que se multiplicaron por cinco, desde los 137 millones de maravedíes en 1654 hasta 644 en 1679. Por supuesto, parte de este crecimiento fue el fruto de la transferencia a Madrid de impuestos previamente cobrados por la Real Hacienda, las llamadas "Sisas Reales», cuyo valor creció de 14 millones de maravedíes en 1654 a 287 en 1679. Debe recordarse que desde el mismo instante en que estos tributos se transferían a la hacienda municipal a cambio de los donativos, las «Sisas Reales» se consideraban parte de los ingresos ordinarios de Madrid, que gestionó y cobró tales impuestos hasta su desaparición en la primera mitad del siglo XIX y una buena idea de su importancia se puede obtener del hecho de que desde 1678, y durante las dos últimas décadas del siglo, el valor medio anual de las «Sisas Reales» fue casi idéntico al de los impuestos reales todavía controlados en Madrid por la Corona.

Pero la obvia importancia de las «Sisas Reales» no debiera ocultar que tras 1654 Madrid también había introducido nuevos y rentables impuestos. Gracias a esto los ingresos municipales (excluyendo las «Sisas Reales») crecieron desde 139 millones de maravedíes en 1654 a 357 en 1679, de forma que puede afirmarse que la introducción de nuevos impuestos municipales sobre el vino, la carne y el carbón desde 1654 para pagar sus intereses a los «efectistas» tuvo tanta importancia en el crecimiento de los ingresos fiscales de la

10 Según nuestras estimaciones, los ingresos municipales ascendieron a 113 millones de maravedís en 1631. Esta suma cayó a 81 millones en 1642, creciendo de nuevo a 137 en 1653. A lo largo de este período la ciudad introdujo la «Sisa del Vino de la Salud», cobrada sobre el consumo de vino y carbón desde 1637; la «Sisa del Carnero de Hospitales» sobre el consumo de carnero en 1644; la «Sisa del Vino de Lérida» sobre el consumo de vino desde 1644 y por último la «Sisa de la Segunda Blanca del carbón», recaudada desde 1649.

11 HOZ GARCÍA, XXV (Madrid, 1988): 372 y ss. y ANDRÉS UCENDO, 5 (Madrid, 2006): 66-68. 
villa como la transferencia a la misma de los impuestos reales que se produjo en el mismo período ${ }^{12}$.

La continua alza de los ingresos de Madrid tuvo consecuencias duraderas. Gracias a la transferencia de las «Sisas Reales» y a la creación de nuevos impuestos municipales, primero, desde la segunda mitad del siglo XVII Madrid fue, con mucho, la ciudad con los mayores ingresos de Castilla y mantuvo esta posición durante todo el siglo XVIII, aunque, como es fácil de comprender, la mayoría de estos ingresos se destinó a pagar los intereses de la deuda municipal, financiando de forma indirecta la política exterior de la Corona antes que las necesidades ordinarias de la ciudad ${ }^{13}$.

Más relevante para los fines del presente trabajo es el hecho de que una parte sustancial de los ingresos recaudados por la Corona y en especial la ciudad procedían de tributos sobre el vino y la carne. Los principales tributos cobrados por la Real Hacienda en Madrid eran la alcabala, los cuatro unos por ciento y los millones, más la renta del tabaco. La alcabala y los cientos gravaban todas las compraventas, con la destacada excepción del pan ${ }^{14}$. Los millones fueron creados en 1590 y después de una breve interrupción su cobranza se reintrodujo en 1601, manteniéndose — como la alcabala y los cientoshasta las reformas liberales de la primera mitad del siglo XIX. Los millones pronto se convirtieron en el impuesto más importante de la Hacienda Real, y a diferencia de los cientos y alcabala su peso cayó sobre un reducido grupo de productos como el vinagre, el aceite de oliva, y en especial la carne y el vino, de forma que su introducción marcó el inicio de una tendencia en virtud de la cual los tributos sobre el vino y las carnes pronto alcanzaron un lugar central en las fuentes de ingresos fiscales de la Monarquía.

Una tendencia similar se desarrolló en la Hacienda Municipal durante el mismo período. Siguiendo el ejemplo de la Corona, las autoridades municipales adoptaron una política fiscal presidida por la constante introducción de tributos indirectos, entre los cuales destacaron los que gravaban el vino y la carne. A finales del siglo XVII, el valor anual de las pagas de los impuestos sobre el vino y la carne representaban casi el 66-72\% del valor global de todos los impuestos — reales y municipales - cobrados en la ciudad, siendo

12 En mayo de 1657 la ciudad creó la «Sisa del Vino de Olivenza», cobrada sobre el vino. Nuevos, y muy rentables, impuestos sobre el vino se añadieron en 1663 y 1667, cuando Madrid introdujo la «Sisa del Vino de Bajada de Medidas» y la «Sisa del Vino de Quiebras de Millones». A lo largo de este período la capital también creó impuestos sobre el carbón (en 1660 y 1666), y sobre el azúcar (en 1660). HOZ GARCÍA, 1988: 372-79.

13 Por citar un ejemplo, en algunos años de las últimas décadas del siglo XVII Madrid llegó a invertir alrededor del $80-90 \%$ de sus ingresos en el pago de los intereses de la deuda municipal. ANDRÉS UCENDO, 30/3 (Roma, 2001): pág. 73.

14 Esta virtual exención ya está presente en la segunda mitad del siglo XVI, según ALVAR EZQUERRA, 1989. 
reseñable que el valor de los tributos municipales sobre ambos productos rebasaba con mucho al de los reales, según se desprende de la tabla 1:

TABLA 1: VALOR MEDIO ANUAL DE LOS TRIBUTOS SOBRE EL VINO Y LA CARNE COBRADOS EN MADRID POR LA CORONA Y EL MUNICIPIO, 1681-1700 (EN MILLONES DE MARAVEDÍS AL AÑO)

\begin{tabular}{ccccccc}
\hline & \multicolumn{2}{c}{ Vino } & \multicolumn{2}{c}{ Carne } & Vino y Carne & $\begin{array}{c}\text { Todas las } \\
\text { especies } \\
\text { gravadas }\end{array}$ \\
\cline { 2 - 7 } & Corona & Madrid & Corona & Madrid & Ambos & Ambos \\
\hline $1681-85$ & 65 & 213 & 17 & 138,4 & 433,5 & 656 \\
$1686-90$ & 65 & 173 & 14,5 & 136,4 & 389 & 548 \\
$1691-95$ & 62 & 175 & 18 & 139 & 394 & 552 \\
$1696-00$ & 61 & 169 & 16 & 141,4 & 387,5 & 554 \\
\hline
\end{tabular}

Fuente: AHN, Consejos, libro 7222.

Los datos de la tabla 1 sugieren que la influencia de la fiscalidad, y en particular de la fiscalidad municipal, sobre los precios del vino y la carne en Madrid debió de ser alta a lo largo de las últimas décadas del siglo XVII. Otra ilustración más exacta de esta tendencia puede encontrarse en la Tabla 2, que muestra la influencia de los impuestos municipales y reales sobre los precios del vino, la carne y el carbón vegetal en la capital entre 1596 y 1700:

TABLA 2: INFLUENCIA DE LOS IMPUESTOS REALES Y MUNICIPALES EN LOS PRECIOS AL POR MENOR DEL VINO, CARNERO Y CARBÓN VEGETAL, MADRID, 1596-1700 (EN PORCENTAJE DEL PRECIO TOTAL)

\begin{tabular}{ccccccc}
\hline & \multicolumn{2}{c}{ Vino } & \multicolumn{2}{c}{ Carnero } & \multicolumn{2}{c}{ Carbón } \\
\cline { 2 - 7 } & Municipales & Reales & Municipales & Reales & Municipales & Reales \\
\hline $1596-00$ & 6,6 & 4 & - & 4 & - & 4 \\
$1601-05$ & 6,2 & 16,5 & - & 6,8 & - & 4 \\
$1606-10$ & 7,3 & 19,1 & 3,3 & 7 & - & 4 \\
$1611-15$ & 9,5 & 17 & 3,7 & 7,8 & - & 4 \\
$1616-20$ & 14,1 & 16,7 & 3,9 & 8,1 & - & 4 \\
$1621-25$ & 17,2 & 14,6 & 3,4 & 6,6 & - & 4 \\
$1626-30$ & 16,6 & 13,7 & 2,8 & 6,8 & - & 4 \\
$1631-35$ & 18,4 & 18,2 & 3 & 8 & - & 4 \\
$1636-40$ & 13,6 & 31,3 & 3,1 & 14,9 & - & 4,4 \\
$1641-45$ & 12 & 39,2 & 4,8 & 17,2 & 12,5 & 5,7 \\
$1646-50$ & 14,5 & 38,4 & 7,4 & 15,9 & 27 & 6 \\
$1651-55$ & 14,3 & 31,6 & 7,6 & 14 & 39,8 & 6
\end{tabular}




\begin{tabular}{ccccccc}
\hline & \multicolumn{2}{c}{ Vino } & \multicolumn{2}{c}{ Carnero } & \multicolumn{2}{c}{ Carbón } \\
\cline { 2 - 7 } & Municipales & Reales & Municipales & Reales & Municipales & Reales \\
\hline $1656-60$ & 23,4 & 30,6 & 16,7 & 13,7 & 38,8 & 6,9 \\
$1661-65$ & 31,1 & 28,1 & 19 & 12,8 & 51,5 & 7,1 \\
$1666-70$ & 47,1 & 17 & 20,3 & 9,1 & 53,3 & 8 \\
$1671-75$ & 49,4 & 17 & 22,8 & 8 & 53 & 8 \\
$1676-80$ & 50 & 15 & 20,5 & 8 & 43,3 & 8 \\
$1681-85$ & 53,8 & 14 & 27,5 & 8 & - & 8 \\
$1686-90$ & 50 & 11,8 & 30,5 & 6 & - & 6 \\
$1691-95$ & 46,9 & 11,8 & 26 & 6 & - & 6 \\
$1696-00$ & 52,6 & 11,9 & 26,2 & 6 & - & 6 \\
\hline
\end{tabular}

Fuentes: Los precios e impuestos sobre el vino pueden hallarse en AHN, Consejos, libros 12001285. Para los precios del carnero y del carbón: AP, Patronato. Santa Isabel, libros 1-28. Para los impuestos sobre el carnero y carbón, HOZ GARCÍA, XXV (Madrid, 1988): 377-79.

De acuerdo con nuestras estimaciones, la influencia de la imposición indirecta sobre los precios al por menor de los productos de la Tabla 2 aumentó de forma continua durante el siglo XVII. Si en los años 1596-1600 los impuestos reales y municipales sobre el vino y la carne de carnero representaban el 10,4 y el $4 \%$ de su precio al por menor, un siglo después este porcentaje había crecido hasta el 64,5 y el 32\% respectivamente, siendo digno de mención el papel de los impuestos municipales en ambos casos. La tributación también ejerció una fuerte, aunque más reducida en el tiempo, influencia sobre los precios del carbón. Como puede verse, los impuestos cobrados sobre este producto surgieron desde algo más del $4 \%$ de su precio de venta en 163640 al 51,3 en 1676-80, alza que puede atribuirse casi de forma exclusiva a la creación durante ese período de cuatro impuestos municipales: la primera, segunda, tercera y cuarta blancas del carbón. Precisamente, la convicción de que la carga fiscal sobre este producto era excesiva hizo que las autoridades de la villa retiraran las blancas del carbón a inicios de $1680^{15}$.

Estamos peor informados acerca de la influencia de la tributación sobre otros productos. Aunque conocemos los principales impuestos cobrados por la Corona y el municipio a lo largo del siglo, hasta ahora no hemos localizado datos de precios fiables del pescado, la fruta, aceite vegetal, huevos, pimienta y textiles en Madrid entre 1596 y 1700, por lo que hemos recurrido a los precios del aceite, fruta, pescado, huevos y pimienta suministrados por E. Hamilton en sus clásicas obras y a los precios de la vara de paño pardo adquirida por los colegios jesuitas de Huete y Villarejo de Fuentes (en la provincia de

15 HOZ GARCÍA, XXV (Madrid, 1988): 372-79. 
Cuenca). Gracias a esto hemos obtenido una idea aproximada del modo en que la tributación pudo haber afectado los precios de estos productos ${ }^{16}$.

A fines del siglo, los impuestos sobre el aceite de oliva representaban el $33 \%$ de su precio de venta, mientras que la influencia de los tributos sobre los precios de los otros productos del párrafo anterior parece haber sido menor, como puede deducirse del hecho de que los impuestos sobre el pescado, fruta, huevos, pimienta y paño pardo fueran el 6\% de su precio de venta. Esta diferencia puede explicarse porque, como en los casos del vino y la carne de carnero, Madrid había creado importantes tributos sobre el aceite de oliva (que en $1696-1700$ representaban el $27 \%$ de su precio de venta) mientras que renunció a introducir impuestos sobre la fruta, huevos, pimienta y paño pardo, que a fines del siglo sólo eran gravados por la alcabala y los cientos recaudados por la Corona ${ }^{17}$.

Teniendo en cuenta el peso del vino, la carne y el aceite de oliva en los modelos de consumo de los castellanos, todo lo anterior otorga en principio credibilidad a la visión más tradicional acerca de la influencia de la tributación sobre los precios y salarios reales expuesta al inicio y que nos proponemos reconsiderar de nuevo en las dos próximas secciones de este trabajo.

\section{Precios y SAlarios}

El primer paso para estudiar la trayectoria del índice de precios en Madrid ha sido reconstruir una cesta de la compra representativa de los modelos de consumo predominantes entre los albañiles madrileños a lo largo del período cubierto por nuestro estudio.

Aunque las dificultades del estudio de los modelos de consumo de las poblaciones urbanas durante la Edad Moderna son bien conocidas, hay al menos dos presupuestos de consumo que pueden ser usados como base para el análisis de los modelos de consumo de la población urbana castellana durante los siglos XVII y XVIII. El primer presupuesto fue presentado por Fernando Álvarez de Toledo a las Cortes de Castilla durante la tercera década del siglo. Según su autor, este presupuesto reflejaba los modelos de consumo de los trabajadores urbanos de las ciudades castellanas de la época, por lo que a simple vista sería un presupuesto apropiado para los fines de nuestro trabajo,

16 Los precios del pescado, aceite de oliva, fruta, huevos y pimienta pueden encontrarse en HAMILTON, 1975: 388-93; 273-90. Para los precios de «paño pardo», AHN, Clero, Jesuitas, libros 32, 36, 39, 224, 281283 y 284.

17 Como se ha indicado más arriba, Madrid había creado impuestos monetarios sobre el pescado en 1581 para pagar las «Sisas Ordinarias», aunque tales impuestos se retiraron en 1686, Madrid. HOZ GARCÍA, XXV (Madrid, 1988): 372-79. 
pero el principal problema de los cálculos ofrecidos por Fernando Álvarez de Toledo reside en el peso excesivamente alto que otorga a los textiles ${ }^{18}$. Según su autor, cerca del $33 \%$ de los gastos diarios de un consumidor castellano se dedicaban a la compra de textiles, mientras que sólo un pequeño $13,5 \%$ se invertía en la adquisición de pan. Teniendo en cuenta lo que sabemos acerca de los modelos de consumo en Castilla y en Europa a lo largo de este período, estos porcentajes son difíciles de admitir y por este motivo hemos preferido no usar este presupuesto ${ }^{19}$.

Un ilustrado bien conocido, Nicolás de Arriquíbar, publicó en 1779 un presupuesto que ofrece algunas ventajas en comparación con el que presentó más de un siglo antes Fernando Álvarez de Toledo a las Cortes. Según Arriquíbar, el consumidor madrileño destinaba a la compra de manufacturas un $20 \%$ de su gasto diario - incluyendo muebles y calzado-, mientras que el precio del pan crecía desde el 13,5\% en el presupuesto de Álvarez de Toledo a un más aceptable $21,7 \%^{20}$. Que el presupuesto de Arriquíbar fuera considerado por su autor representativo de los modelos de consumo predominantes entre los trabajadores de la capital es otra ventaja nada desdeñable, y esto nos ha animado a usarlo como base para elaborar la cesta de la compra en este trabajo para estudiar la evolución de los precios en la capital que se muestra en la Tabla 3:

TABLA 3: CESTA DE LA COMPRA DE UN ALBAÑIL MADRILEÑO, 1596-1700

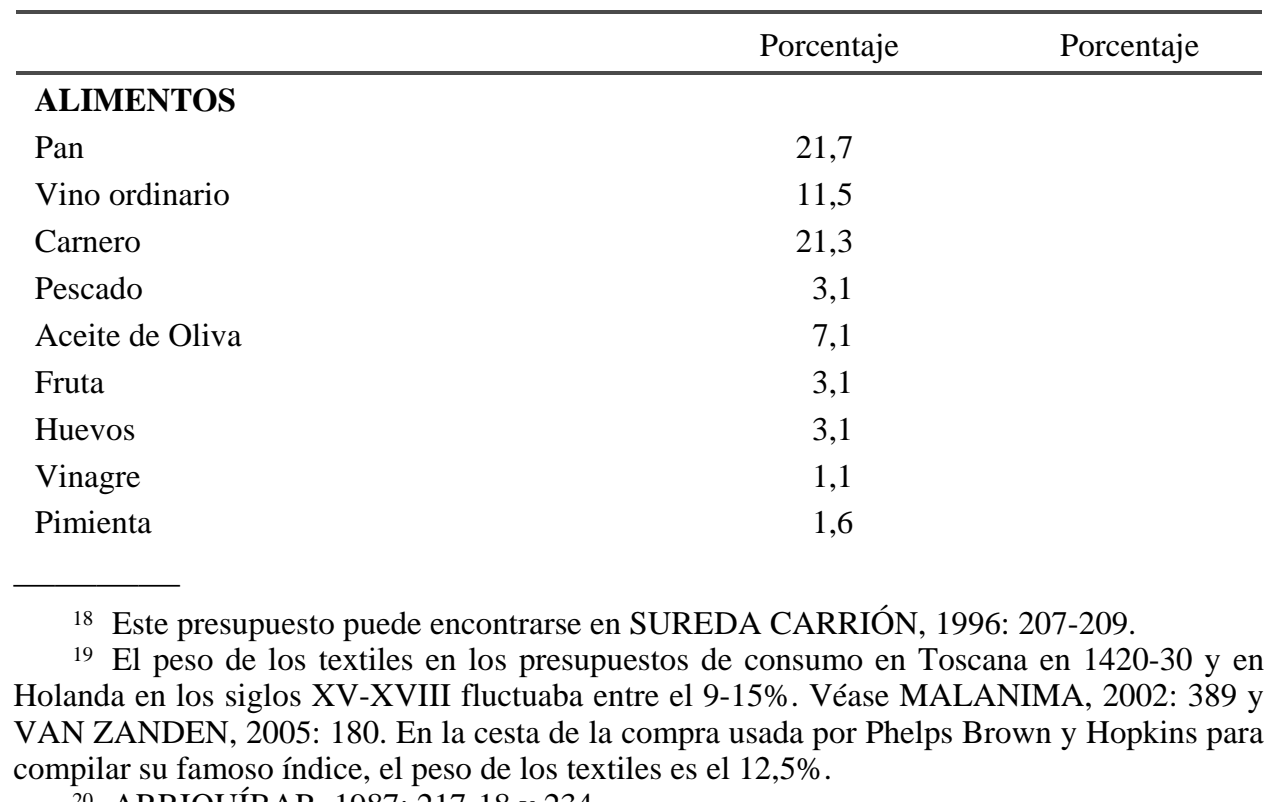

20 ARRIQUÍBAR, 1987: 217-18 y 234. 


\begin{tabular}{lcc}
\hline & Porcentaje & Porcentaje \\
\hline TOTAL ALIMENTOS & & $\mathbf{7 4 , 3}$ \\
Carbón & 4 & \\
Paño & 21,7 & \\
TOTAL MANUFACTURAS & & $\mathbf{1 0 0}$ \\
\hline
\end{tabular}

Fuente: Arriquíbar, Nicolás de, Recreación Política, págs. 217-34.

Podría alegarse, de forma correcta, que nuestra cesta se resiente de algunas carencias. Por ejemplo, Arriquíbar incluyó en su cesta productos como las legumbres y los vegetales y servicios como los alquileres. En conjunto, estos bienes y servicios representaban casi el 10\% del gasto diario de los madrileños y, como puede verse, han sido excluidos de nuestro índice debido a las limitaciones de nuestras fuentes ${ }^{21}$. También podría decirse que nuestros precios de la carne son los del carnero. Siendo la carne de carnero una variedad consumida por los sectores más privilegiados de la sociedad castellana, hubiera sido más apropiado incluir en nuestra cesta otros tipos de carnes, como el cerdo o la vaca, pero de nuevo esto ha sido imposible a causa de las limitaciones de nuestras fuentes, aunque esperamos resolver este problema en el futuro. No obstante, este problema es menos importante de lo que parece si consideramos, por una parte, que los dispersos datos de los que disponemos sugieren que la trayectoria de los precios del carnero, vaca y cerdo en Madrid a lo largo del período debió de ser similar y, por otra, que el consumo de carnero era proporcionalmente más importante en el siglo XVII que en el XVIII ${ }^{22}$.

Por otro lado, las ventajas de nuestra cesta superan sus desventajas. En primer lugar, nuestra cesta incluye los precios del pan y a esto debe añadirse, en segundo, que también hemos incluido los precios al por menor del vino,

21 El presupuesto que utilizan LLOPIS y GARCÍA MONTERO, 2009: 10-13, incluye algunos productos más, pero difiere sobre todo en el sentido de reducir un poco el peso de la alimentación y sobre todo el de los tejidos, a la vez que incluye el alquiler, cuyos valores para el siglo XVII no es fácil averiguar debido a las lagunas que presenta la documentación. En cualquier caso, el presupuesto descansa sobre las estimaciones del consumo medio de la población madrileña c. 1789 que recientemente ha elaborado BERNARDOS, 2008: 553-555. El mismo Nicolás de Arriquíbar dice haber considerado al consumo medio de los madrileños veinte años antes a la hora de elaborar su presupuesto.

22 En 1673 los precios de la libra de carnero y puerco fresco habían alcanzado un índice 297 y 275 respectivamente desde una base 100 en 1597. Aunque estamos menos informados sobre los precios de la carne de vaca, su tendencia parece haber sido análoga a la de los precios de la libra de carnero, al menos durante el primer tercio del siglo. Medido en una base 100, los precios del carnero alcanzaron un índice 181 (desde una base 100 en 1596), mientras en el mismo año los precios de la carne de vaca habían alcanzado el índice 200. Sobre el cambio en las pautas del consumo de carne de los madrileños, de BERNARDOS, 2008: 558. 
carne y carbón, y que éstos incluyen el efecto de los impuestos (municipales y reales) cobrados sobre estos productos en la capital entre 1596 y $1700^{23}$. En cuanto a los demás productos de la cesta, hemos usado los precios aportados por E. Hamilton en sus trabajos, con la excepción de los textiles, cuyos precios proceden de las compras de paño pardo de los colegios jesuitas de Villarejo de Fuentes y Huete.

En la actualidad estamos trabajando en la recopilación de precios del pescado, aceite de oliva, fruta, tocino, huevos, pimienta, calzado, paños y lienzos en Madrid entre 1596 y 1700, por lo que el índice de precios que hemos obtenido usando la cesta de la compra de la Tabla 3 y presentado más adelante, en el Gráfico 1 posee un carácter provisional. Esperamos poder presentar un índice definitivo en un futuro cercano, aunque nos gustaría resaltar que en su estado actual nuestro índice de precios puede considerarse representativo de la evolución de los precios en el Madrid del Seiscientos. Después de todo, este índice incluye los precios al por menor del pan, vino ordinario, carne y carbón, productos en los que los albañiles de la capital invertían el 60\% de su gasto diario, siendo el vino, la carne y el carbón - junto con el aceite de oliva- los productos más gravados de nuestra cesta de la compra, por lo que hay motivos para alegar que la inclusión de nuevos datos con precios de la carne de vaca, cerdo, pescado, aceite de oliva, fruta, huevos, vinagre, pimienta y tejidos no modificará demasiado los resultados de nuestro análisis.

Las repercusiones de la fiscalidad municipal sobre los precios no terminan ahí, por cuanto el coste de la vida en aumento debió erosionar el poder de compra de los salarios en una medida que desconocemos, pero cierta. No en vano, Miguel Caxa de Leruela escribía al respecto en 1631 que «no le bastan a un jornalero ocho reales, que gana cada día en esta corte, después que los precios se alteraron con tanta exorbitancia» ${ }^{24}$.

Sin embargo, la evolución de los salarios nominales en el Madrid de los Austrias no se conoce bien todavía, a pesar de la importancia que el mercado laboral de la villa y corte representaba en comparación con otras ciudades españolas. Hamilton reconocía que hasta 1737, cuando comienza la construcción del nuevo Palacio Real sobre los cimientos del antiguo Alcázar, que se había quemado en la Nochebuena de 1734, no es posible disponer de datos suficientemente continuos para medir las fluctuaciones a corto plazo del salario monetario o las diferencias salariales entre diferentes clases de mano de obra $^{25}$. De hecho hay en su obra una importante laguna a partir de 1650 que llega justamente hasta 1737, mientras que los datos de la época anterior no

23 Para los precios del vino, AHN, Consejos, libros 1200-1285. En cuanto a los precios del pan, carnero y carbón, AGP, Patronatos, Santa Isabel, libros 1-29.

24 CAXA DE LERUELA, 1975: 101-102.

25 HAMILTON, 1988: 246. REHER y BALLESTEROS, E, XI/1 (Madrid, 1993): 106, han tratado de corregir esta laguna de 1650 a 1737 interpolando los datos de Valencia. 
parecen ser representativos del caso concreto de Madrid. Primero porque en los índices aparecen mezclados oficios y categorías de localidades distintas ${ }^{26}$. Segundo, y más importante, porque el salario de jornalero, que podría ser el más representativo en virtud de su continuidad, procede sucesivamente de Castilla la Vieja hasta 1550, de Castilla la Nueva desde entonces hasta 1600 y de Andalucía en la primera mitad del siglo XVII. Como los niveles salariales eran mayores en las regiones meridionales que en la meseta, este procedimiento tiende inevitablemente a exagerar la tendencia al alza que se observa en la evolución de los salarios nominales a principios del siglo XVII. En consecuencia, hay dos buenas razones que justifican sobradamente la necesidad de construir un nuevo índice de salarios monetarios de Madrid.

La documentación de algunas grandes corporaciones civiles y eclesiásticas puede sernos de gran utilidad. Es el caso del Alcázar Real y del Real Colegio de Santa Isabel, concretamente de las cuentas de los pagadores de las obras reales $^{27}$ y de los libros de gasto extraordinario ${ }^{28}$, respectivamente. En ambos casos aparecen reiteradas indicaciones acerca del jornal diario pagado a diversos empleados por la ejecución de ciertas obras, y, en el primero se incluyen, concretamente, numerosas nóminas semanales donde se indican los nombres de los empleados, su categoría, los días que trabajaron y el jornal diario que se les pagó. Aunque ciertamente se han conservado de forma fragmentaria, estos datos tienen el interés añadido de ser de la misma naturaleza que los utilizados por Hamilton a partir de 1737.

El salario que mayor interés despierta es el de peón de albañil. Las referencias documentales a este oficio son las más frecuentes, como corresponde sin duda al hecho de ser el más numeroso entre la población activa de Madrid. La construcción se convirtió muy pronto en el principal ramo de actividad urbana $^{29}$. Aunque a causa de las limitaciones de las fuentes es difícil conocer el peso de este sector en la fuerza de trabajo de la villa en el siglo XVII, gracias al Censo de Artes y Oficios de 1757 sabemos que los 4.127 peones de albañil registrados en el mismo representaban el $66 \%$ de los 6.247 trabajadores de la construcción y el 24 \% de un total de 17.506 empleados en la industria y la manufactura ${ }^{30}$. En relación con todos los perceptores de ingresos, a

26 FELIU, 1999, vol. 1: 89, nota 23, ha recordado este importante detalle.

27 AGS, Contaduría Mayor de Cuentas, $3^{\text {a }}$ época, legajos 765, 784, 897, 1306, 1362 , 1369, 1373, 1409, 1450, 1452, 1461, 1475, 1810 (2), 1874 (5), 1893 (19), 2745 (27), 2995 (2), 3156 (8) y Casa y Sitios Reales, leg. 247 y AGP, Pardo, cajas 9380 a 9401. Una breve referencia a este último fondo documental se encuentra en LÓPEZ GARCÍA, 1988: 272.

28 AGP, Santa Isabel, legajos 1 a 34.

29 Y de otras ciudades en general. De hecho, el estudio comparativo de ALLEN, 38 (Orlando, 2001): 411-447, se refiere a los salarios de peón de albañil de varias ciudades europeas. También FELIU, 1999, vol. 1: 89.

30 PINTO CRESPO y MADRAZO MADRAZO, 1995: 171 y 203, y NIETO SÁNCHEZ, 2008: 328-329. 
mediados del XVIII la construcción era «la actividad dominante industrial, con el $16 \%$ de la fuerza laboral», sólo sobrepasada por el servicio domésti$\mathrm{Co}^{31}$. Esta proporción debía de ser todavía mayor si damos por hecho que una gran parte de la población inmigrante, que se alojaba en posadas públicas y casas particulares, pero que no aparece registrada en el Catastro, eran trabajadores de la construcción ${ }^{32}$. Los datos del siglo XVII no podían ser muy diferentes si consideramos el intenso ritmo de actividad inmobiliaria que se vivió durante las etapas de rápido crecimiento de la villa de Madrid.

Los jornales no se fijaban a través de una tasa oficial, sino de acuerdo con las condiciones del mercado, «como en otras obras conforme a los tiempos», en palabras del maestro mayor Juan Gómez de Mora ${ }^{33}$. Siguiendo una larga tradición recogida en la legislación castellana, los trabajadores concurrían por sí o en cuadrillas a la plaza pública donde se fijaban los jornales de acuerdo con las condiciones de la oferta y la demanda ${ }^{34}$. Además, por razones de orden práctico, las instrucciones de las obras reales reconocían que los oficiales y peones debían ser pagados «como merecen» a fin de asegurar por este medio la concurrencia de los más hábiles, trabajadores y productivos, pues de otro modo no podía esperarse una obra bien acabada 35 .

La investigación ha señalado que en ciudades como Barcelona y Londres los albañiles empleados en las grandes obras, que ofrecían una ocupación continuada durante bastante tiempo, percibían unos salarios menores que sus colegas que trabajaban en obras de menor entidad y por eso se ha llegado a cuestionar la representatividad de los jornales percibidos por quienes trabajaban en los grandes programas de construcción de las monarquías de la época ${ }^{36}$. Ahora bien, que esto fuera así dependería sobre todo del volumen de empleo respecto a las obras de los demás establecimientos, civiles y religiosos, públicos y privados, y también de la forma en que se fijaban los salarios. Según sugiere el comentario de Juan Gómez de Mora que acabamos de citar, los salarios de los peones de albañil que trabajaban en el Real Alcázar se establecían según las

31 RINGROSE, 1985: 91.

32 LARQUIÉ y FAYARD, 4 (Madrid, 1968): 237 y LANZA GARCÍA, 2011: 480-490, por lo que se refiere a 1665 y 1708 , respectivamente.

33 Cit. por TOVAR MARTÍN, 1983: 484.

34 Las ordenanzas de la villa Madrid de 1351 ya fijaban la plaza pública como lugar de contratación. Concretamente, los obreros de la construcción acudían a la plaza de San Vicente, según Nieto Sánchez, J., Artesanos y mercaderes, pág. 158. El mismo procedimiento era reconocido en las Cortes de Toro de 1369 y las de Valladolid de 1548. Véase Novísima Recopilación, Título XXVI, Ley I.

35 El procedimiento de contratación y supervisión de las obras reales se recoge en sucesivas «Instrucciones». Véase DÍAZ GONZÁLEZ, 2002: 54 y 145, entre otras, así como AZCÁRATE, 24 (Valladolid, 1960): 223-230. En la construcción el trabajo asalariado fue predominante en toda Europa desde muy pronto, según THRUPP, 1979: 285.

36 BOULTON, 1979: 280. 
condiciones de mercado, y de hecho los jornales pagados por la Casa Real se repiten en el colegio de Santa Isabel con muy contadas excepciones, que se concentran en las décadas de 1660 y 1670 . Un reflujo de la oferta de mano de obra, según cabe deducir de la evolución demográfica de la villa ${ }^{37}$, en relación con la demanda, que se reanima entonces un poco sobre todo por iniciativa de los promotores eclesiásticos, bastaría para explicar las dificultades de los particulares para conseguir trabajadores, viéndose forzados necesariamente a pagarla un poco más que las obras reales.

El jornal diario no era uniforme a lo largo del año y variaba de acuerdo con la duración de la jornada laboral. Lo normal en las obras de la Corona, según las Instrucciones de 1564, era llegar al tajo a las seis de la mañana, parar a las once durante dos horas para comer y echar la siesta, volver a la una, descansar otra hora de cuatro a cinco y terminar la jornada con la puesta del sol. En invierno se empezaba a las siete y sólo se paraba una hora para comer ${ }^{38}$. Aunque en las obras del Buen Retiro el jornal podía ser un real más alto en verano que en invierno, en las nóminas del Alcázar la diferencia no pasaba de un cuarto o medio real como mucho, según las épocas. Sin embargo, a la hora de establecer el jornal anual es más adecuado el valor modal que el valor medio, en la medida que es preferible adoptar la cifra dominante que ofrecer una aparente exactitud «media». Además, con ello se tiende a establecer la tarifa socialmente aceptada, «lo que ganaba» un oficial o un peón de un oficio determinado ${ }^{39}$.

La cuestión de los pagos en especie puede plantear un problema mayor. Sabemos que a la Sala de Alcaldes llegaron algunos informes que destacaban la conveniencia de vender el pan no sólo en las tahonas sino también en las tiendas de abastos, que era el lugar donde los «trabajadores, lavanderas y pasajeros... ocurren de noche [o] a las oras que cada uno puede» ${ }^{40}$. De hecho, no hay constancia de remuneraciones adicionales en especie a los jornaleros, como era habitual en el caso de los trabajadores ordinarios de los sitios reales, si acaso algún refresco en el colegio de Santa Isabel, pero en ocasiones señaladas. En Valladolid todo parece indicar que la costumbre antigua de pagar almuerzo y merienda que recogían las ordenanzas municipales de 1552 había quedado en desuso en el siglo XVII, reduciéndose todo lo más a ciertos convites de vino ${ }^{41}$. Así lo confirma en parte un informe del Consejo de Castilla de 1646 en el que se afirma que «los más lugares del Reyno se componen de labradores y jornaleros que comen a sus expensas, los que sirben en casas de grandes y títulos y otros respecto del resto del pueblo son poquísimos y estos

37 CARBAJO ISLA, 1987: 223-227.

38 AZCÁRATE, 24 (Valladolid, 1960): 223-230.

39 De acuerdo con las atinadas observaciones de FELIU, 1991, vol. 2: 70, siguiendo a Pierre Vilar. Véase también BOULTON, XLIX/2 (Oxford, 1996): 275-281.

40 AHN, Sala de Alcaldes, libro 1285, fol. 47.

41 GUTIÉRREZ ALONSO, 1989: 176. 
no en todos los lugares, sino en la corte y otras ciudades populosas, y destos pocos que sirven, reciben los más la ración en dinero» ${ }^{42}$.

Nuestros datos de precios, completados con los de Hamilton, y los jornales percibidos por los peones de albañil ocupados en el Alcázar Real y en el Real Colegio de Santa Isabel han servido para elaborar el Gráfico 1, en donde se compara la trayectoria del índice de precios en Madrid entre 1596 y 1700 con la de los salarios nominales percibidos por un peón de albañil en el mismo período:

GRÁFICO 1: ÍNDICES DE PRECIOS Y DE SALARIOS NOMINALES DE UN PEÓN ALBAÑIL, MADRID, $1596-1700(1616-20=100)$

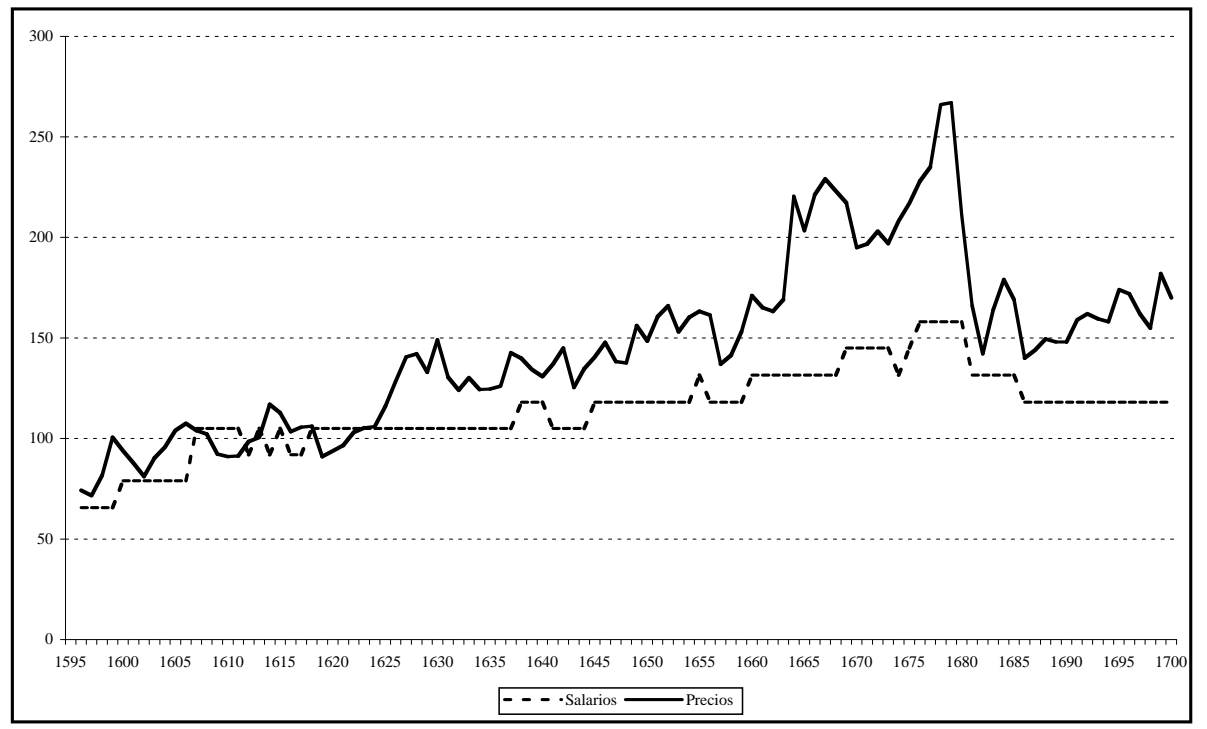

Fuente: Véase texto.

El Gráfico 1 muestra que los precios tendieron a crecer en Madrid a lo largo del período. Durante la primera fase, entre 1596 y 1639, los precios crecieron alrededor de un 50\%, desde un índice 84 en 1596-1600 a 138,5 en 162630. La tendencia alcista del índice de precios se fortaleció durante la segunda fase, que abarcó las décadas centrales del siglo, cuando los nuevos impuestos reales y municipales junto con las manipulaciones de la moneda de vellón propiciaron un nuevo y sustancial alza del nivel de precios, que creció del índice 127 en 1631-35 a 241,5 en 1676-80, culminando en los años 1678-79, cuando los precios alcanzaron los índices 266 y 267 respectivamente.

42 AHN, Consejos, leg. 7158, expte. 60. 
Las fuertes alzas de precios típicas despertaron el interés de las autoridades castellanas e impulsaron la puesta en práctica de una política de reforma monetaria, que, en combinación con importantes descuentos fiscales, ayuda a explicar el brusco descenso del nivel de precios de inicios de los 80. El Gráfico 1 muestra que después de las medidas deflacionarias de la primera parte de la década, los precios cayeron un 40\% desde el índice 241,4 en 1676-80 a 146 en 1686-90, aunque debe recordarse que durante las dos últimas décadas de la centuria los niveles de precios siguieron muy por encima de las cotas del primer tercio del siglo 43 .

La evolución del salario nominal también muestra un alza muy considerable, aunque inferior a la de los precios. En concreto, los jornales crecieron desde los 2,5 reales diarios de 1596 hasta los 4,5 de finales del siglo XVII, valor que permaneció constante hasta bien entrada la segunda mitad del siglo siguiente ${ }^{44}$. Ahora bien, el máximo culminó en 1680, cuando los salarios alcanzaron los 6 reales diarios, antes de producirse una caída brusca a la que sucedió una estabilización en las cotas ya alcanzadas en el segundo cuarto de siglo XVII que prosiguió en el siglo XVIII. La subida se escalonó en varios momentos decisivos que coinciden a finales del siglo XVI con los años de la peste atlántica (1596-1600), y muy poco después con el regreso de la Corte a Madrid en 1607, en un movimiento inverso al que se ha podido observar en Valladolid ${ }^{45}$. A partir de entonces se mantuvo una estabilidad, alterada brevemente en 1637 y desde mediados de la década siguiente, coincidiendo con la peste andaluza, otro de los mayores desastres demográficos de la España Moderna. Por último, con la inflación del vellón comenzó una escalada en 1660 y 1669 que culminó en 1676-1680, aunque el gráfico muestra que tal escalada resultó muy inferior a la del índice de precios y que, de hecho, en estas dos décadas la distancia entre precios y salarios alcanzó su valor más elevado. La drástica deflación provocada por las reformas monetarias de 1680-1686 forzó una rebaja del jornal, que se situó en las cotas del segundo cuarto del siglo XVII. Así, el mayordomo del Real Colegio de Santa Isabel dice haber pagado al maestro de obra que se encargó del retejo de la casa y otros reparos en noviembre de 1684 algo menos de lo acordado en un principio porque «se rebajaron de los jornales» ${ }^{46}$. Del mismo modo que se ha observado en otras ciudades, los salarios madrileños muestran un cierto retraso en relación con los movimientos de los precios: no suben tan pronto como éstos ni se ajustan inmediatamente a la baja, en consecuencia pierden poder adquisitivo en las épocas de inflación, como sugería Miguel Caxa de Leruela

43 Sobre las medidas deflacionarias de los 80, HAMILTON, 1988: 48-63.

44 Así lo indican las cuentas de los pagadores de las obras reales de Madrid que se conservan en AGS, Tribunal Mayor de Cuentas, leg. 1665, años 1738, 1739 y 1746.

45 GUTIÉRREZ ALONSO, 1989: 180.

46 AGP, Patronatos de la Corona, Santa Isabel, leg. 27. 
en el texto anteriormente citado, pero lo conservan e incluso mejoran con la deflación, como en los años de 1680.

El Gráfico 1 muestra que durante el siglo XVII los salarios nominales de los peones de albañil de la capital crecieron, aunque también muestra que desde los años centrales del siglo esta subida fue muy inferior a la de los precios. La distancia entre precios y salarios fue particularmente visible durante los años 60 y 70, y aunque la caída del índice de precios de 1681-85 redujo la distancia entre ambas, merece la pena recordar que en las dos últimas décadas del siglo los niveles de precios todavía estaban muy por encima de los salarios nominales.

El hecho de que desde 1625 aproximadamente los precios crecieran por encima de los salarios sugiere que los salarios reales de los peones de albañil de la villa debieron de caer y el Gráfico 2 presenta la evolución del índice de salarios reales de este grupo, lo que nos permite medir la auténtica dimensión del descenso sufrido por los mismos:

GRÁFICO 2: ÍNDICE DE SALARIOS REALES DE UN PEÓN ALBAÑIL, MADRID 1596-1700 (1616$20=100)$

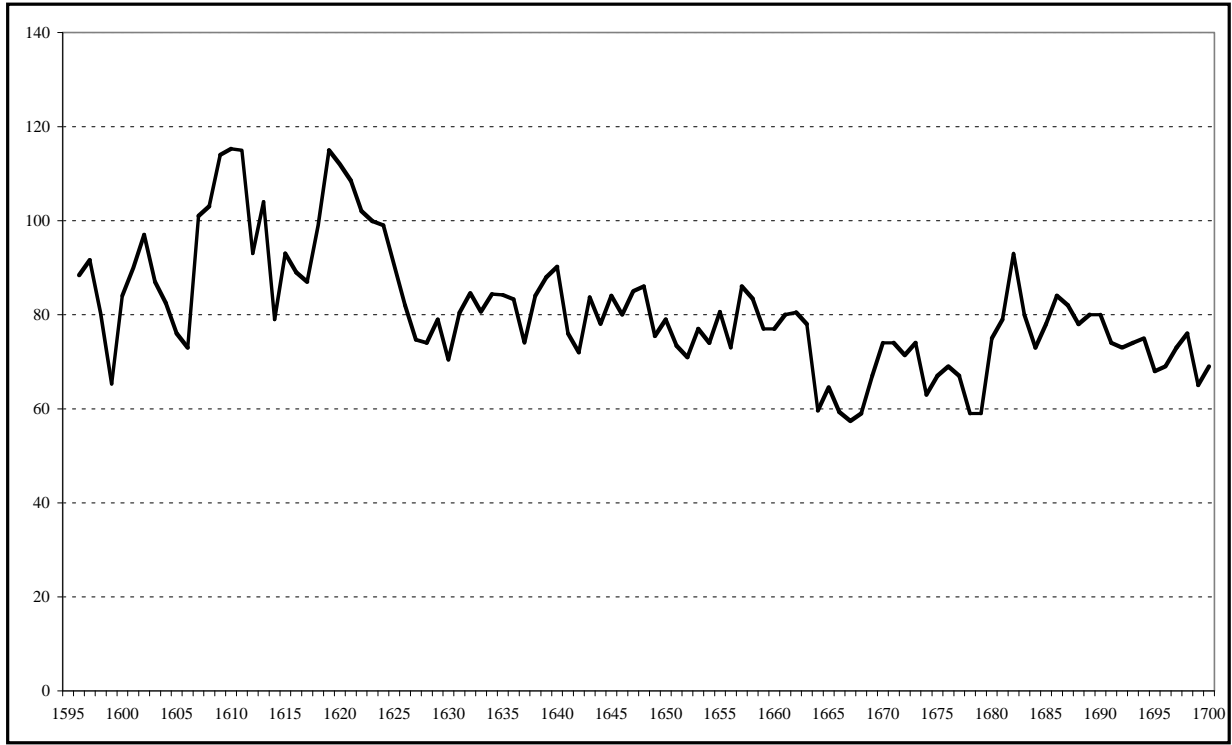

Fuente: Véase texto.

El Gráfico 2 muestra que los salarios reales conocieron una importante subida de 1596 a 1625. Según nuestros cálculos, los salarios reales crecieron de un índice 82 en 1596-1600 a 101 en 1606-10, culminando en 1609 y 1610 en que alcanzaron los índices 114 y 115 respectivamente. Tal crecimiento fue el 
resultado de la creciente demanda de trabajo tras la definitiva llegada de la Corte en 1606. Aunque hubo un descenso en los salarios reales entre 1612 y 1617, fue temporal y estuvo seguido por una nueva e importante subida durante los años entre 1618-25, cuando los salarios reales recuperaron los altos niveles de 1606-10.

Después de 1625 el salario real de los peones de albañil comenzó su caída. En 1626-30 este indicador perdió el 25\% del nivel de 1621-25, pero los peores momentos fueron los años 60 y 70 cuando, como resultado de la creciente diferencia entre el índice de precios y salarios nominales, los salarios reales se redujeron hasta el índice 70 en 1661-65 y en 1671-80 y al índice 63 en 166670. Medido en términos reales, esto significa que durante ambas décadas los salarios reales de los peones de albañil habían perdido alrededor del 30 y del $40 \%$ de los niveles alcanzados en los momentos más brillantes del primer tercio del siglo, aunque en algunos años como 1664, 1666, 1667, 1668, 1678 y 1679 los salarios reales cayeron nada menos que un 50\% con respecto a los picos de 1609 y 1610.

El desplome de los salarios reales durante los años 60 y 70 fue parado por las medidas deflacionarias de inicios de los 80 . El brusco descenso del nivel de precios en 1681-85 facilitó una recuperación de los salarios reales, aunque su alcance fue más reducido de lo que tradicionalmente se ha pensado, algo que también se debió al hecho de que, como se puede ver en el Gráfico 1, los salarios nominales tendieron a caer desde 1681. De hecho, durante las dos últimas décadas del siglo los salarios reales sólo alcanzaron los niveles de 1630-50, apenas superaron los del 1596-1610 y, desde luego, quedaron claramente por debajo de los índices del período alcista de 1606-1625. En consecuencia, puede afirmarse que a partir de 1626 la trayectoria de los salarios reales percibidos por los peones de albañil de la capital fue descendente, sin que las medidas deflacionarias de inicios de los 80 bastaran para alterar esta trayectoria ${ }^{47}$.

\section{EL PESO DE LOS TRIBUTOS}

La Tabla 4 muestra la influencia de los tributos sobre los niveles de precios y salarios reales en el Madrid del siglo XVII. La primera columna de la tabla presenta el índice de precios de la capital del Gráfico 1, mientras que la segunda ofrece ese mismo índice excluyendo los impuestos municipales a fin de obtener una idea del impacto de la fiscalidad municipal sobre los precios. La columna 3 muestra cómo habrían evolucionado los niveles de precios de la

47 Una comparación con otras ciudades europeas puede verse en ALLEN, 38 (Orlando, 2001): 427-430. 
columna 1 en ausencia de tributos municipales y reales. Por último, las columnas 4 y 5 analizan la influencia de los impuestos municipales y reales sobre los salarios reales. La columna 4 representa el índice de salarios reales del gráfico 2, y la 5 presenta cómo habría evolucionado tal índice en ausencia de impuestos, tanto municipales como reales. Todos los datos se presentan en medias quinquenales.

TABLA 4: INFLUENCIA DE LOS IMPUESTOS MUNICIPALES Y REALES SOBRE LOS PRECIOS Y SALARIOS REALES EN MADRID, 1596-1700 (1616-20=100)

\begin{tabular}{lccccc}
\hline & $\begin{array}{c}\text { Precios con } \\
\text { impuestos }\end{array}$ & \multicolumn{2}{c}{ Precios sin impuestos } & \multicolumn{2}{c}{ Salarios reales } \\
& & Municipales & Reales & Con impuestos & Sin impuestos \\
\hline $1596-1600$ & 84 & 85 & 89 & 82 & 77 \\
$1601-1605$ & 92 & 93,5 & 93 & 86,5 & 85 \\
$1606-1610$ & 99 & 100 & 99 & 101 & 100 \\
$1611-1615$ & 104 & 105 & 104 & 97 & 96 \\
$1616-1620$ & 100 & 100 & 100 & 100 & 100 \\
$1621-1625$ & 105 & 105 & 104,5 & 100 & 100,5 \\
$1626-1630$ & 138,5 & 139 & 139 & 76 & 76 \\
$1631-1635$ & 127 & 126,5 & 125,5 & 83 & 84 \\
$1636-1640$ & 135 & 135 & 128 & 88 & 93 \\
$1641-1645$ & 136,5 & 136 & 124 & 79 & 87 \\
$1646-1650$ & 146 & 143 & 131 & 81 & 78 \\
$1651-1655$ & 161 & 158 & 128 & 72 & 91,5 \\
$1656-1660$ & 153 & 143 & 132 & 79 & 84 \\
$1661-1665$ & 184 & 168 & 157 & 72,5 & 74 \\
$1666-1670$ & 217 & 197 & 186 & 63 & 84 \\
$1671-1675$ & 204 & 177 & 170 & 70 & 76 \\
$1676-1680$ & 241 & 214 & 208 & 70 & 96 \\
$1681-1685$ & 164 & 140 & 137 & 81 & 89 \\
$1686-1690$ & 146 & 123 & 119 & 81 & 73 \\
$1691-1695$ & 162,5 & 140 & 135 & 70 & \\
$1696-1700$ & 168 & 145 & 143 & & 96 \\
\hline & & & & 79 & \\
\hline
\end{tabular}

Fuentes: Las mismas que la Tabla 2.

Para estimar cómo afectaron los impuestos reales y municipales a los precios de los productos de nuestro índice de precios, hemos seguido los criterios 
expuestos al final del primer apartado. Estamos bien informados acerca de los tributos cobrados sobre el vino, carne de carnero, carbón y aceite de oliva, por lo que no ha sido difícil calcular la carga fiscal que caía sobre el consumo de estos productos y su influencia sobre los precios. Como también hemos dicho al final del primer apartado, el resto de los productos de nuestro índice — con la excepción del pescado y la pimienta - sólo estaban gravados por la alcabala y los cuatro unos por ciento.

En teoría, la alcabala representaba el $10 \%$ de los precios de los productos, mientras que los cuatro unos por ciento representaban otro $4 \%$, de forma que podría pensarse que la alcabala y los cientos debían de representar el 14\% del precio de los productos de nuestra cesta de la compra, con la destacada excepción del pan, prácticamente exento de tributación en Castilla durante toda la época moderna ${ }^{48}$.

Debe recordarse, sin embargo, que las investigaciones recientes han demostrado de forma convincente que en la mayor parte de los casos la alcabala se recaudaba cobrando un tipo muy inferior al teórico 10\%. En un trabajo anterior hemos mostrado cómo entre 1666 y 1686 el valor medio anual de los cuatro unos por ciento fue casi idéntico al de la alcabala. Esto parece indicar que la alcabala debió de representar alrededor del $4 \%$ de los precios de venta de los productos a lo largo de ese período y hemos decidido considerar que entre 1596 y 1638 todos los productos de nuestro índice, menos el pan, fueron gravados por la alcabala con un tipo del $4 \%$. El primer ciento comenzó a cobrarse en 1639. Puesto que cada ciento representaba un 1\% de los precios de venta de los productos, después de la introducción de los cuatro unos por ciento — realizada de forma escalonada en 1639, 1642, 1657 y 1666-, la alcabala y los cuatro unos por ciento representaba el $8 \%$ de los precios de venta de nuestros productos, porcentaje que se redujo al 6\% en 1686, cuando los cuatro unos por ciento se rebajaron a la mitad ${ }^{49}$.

El caso de la pimienta ofrece otro problema. Aparte de estar gravada por la alcabala y los cientos, este producto también estaba gravado por la renta de la pimienta, introducida a inicios del siglo ${ }^{50}$. Hasta el momento nos ha sido imposible localizar información fiable sobre la repercusión de este monopolio en los precios de la pimienta en la villa, aunque este problema es menos importante de lo que parece a causa del reducido peso de la pimienta en nuestra cesta de la compra.

Según indica la Tabla 4, la influencia de los tributos indirectos sobre los niveles de precios fue pequeña durante el primer tercio del siglo. Comenzó a crecer desde 1631-35, aunque no fue hasta 1656-60 cuando las consecuencias

48 ARTOLA, 1980. DOMÍNGUEZ ORTIZ, 1960: 99 y FORTEA PÉREZ, 1990: 78-79.

49 FORTEA PÉREZ, 1990: 67 y ss. y ANDRÉS UCENDO, 30/3 (Roma, 2001): 614.

50 DOMÍNGUEZ ORTIZ, 1960: 213. 
de la proliferación de tributos municipales y reales sobre los niveles de precios comenzaron a ser relevantes. Las columnas 1 y 3 de la tabla 4 sugieren que a causa de los tributos el índice de precios en Madrid (columna 1) fue entre un $16-20 \%$ mayor a lo que hubiera sido en ausencia de tributos reales y municipales a lo largo del último tercio del siglo, siendo digno de mención que la diferencia entre los dos índices culminó en 1686-90, cuando el índice de precios incluyendo impuestos de la columna 1 estuvo casi un 25\% por encima del índice de precios sin impuestos de la columna 3.

La Tabla 4 también indica que, como era previsible, la influencia de los tributos indirectos sobre los salarios reales también fue importante. De acuerdo con la columna 5, en ausencia de tributos municipales y reales el salario real ganado por un peón de albañil después de 1656-60 hubiera sido superior en un 16-20\% al índice de salarios reales de la columna 4, por lo que es fácil de observar que a fines de siglo la fiscalidad tendió a elevar los niveles de precios en la misma medida en que redujo los salarios reales.

Por supuesto, podría alegarse que este razonamiento es discutible. Como se ha indicado al inicio, la asunción de la inexistencia de impuestos sobre la que descansa este ejercicio es poco realista. Sin tributación, los niveles de precios madrileños habrían experimentado una subida menos pronunciada y, como muestra la caída de los salarios nominales tras las medidas deflacionistas de inicios de 1680 del Gráfico 2, cualquier descenso del nivel de precios hubiera causado una caída de los salarios nominales que a su vez hubiera impulsado un descenso de los salarios reales. Este es el tipo de problema previsible en un ejercicio de este género, por lo que nos gustaría recordar de nuevo que su propósito ha sido proporcionar al lector una estimación de la influencia de los impuestos indirectos sobre los precios y salarios reales para mejorar nuestros conocimientos sobre esta cuestión.

Más importante pudiera ser la observación de que la mayoría de los tributos recaudados por la villa debieran ser considerados, de hecho, como impuestos reales disimulados bajo el manto municipal. Después de todo, el alza de los ingresos de la ciudad fue principalmente debido a la transferencia a Madrid de la mayor parte de los tributos recaudados por la Corona en la ciudad y su distrito fiscal — «Sisas Reales»— y a la paralela creación de nuevos impuestos municipales a cambio de los donativos concedidos por la ciudad a la Real Hacienda durante la segunda década del siglo.

Esto es innegable, pero más que al destino de las sumas recaudadas por la Hacienda Municipal habría que atender al hecho de que ambos tipos de impuestos fueron incluidos, desde un punto de vista legal, entre las fuentes de ingresos ordinarios de la villa, y que ésta controló su gestión y cobro con total independencia de la Corona, algo que tuvo consecuencias duraderas que probablemente nadie pudo haber previsto en 1653.

Desde 1670 la Real Hacienda adoptó medidas para reducir la carga fiscal que caía sobre el reino, y esta política se aceleró entre 1682 y 1686. En 1670 
la Corona decidió suprimir uno de los servicios de millones más importantes, el servicio de las Quiebras de millones, y en 1683 se introdujeron notables recortes en la carga fiscal. La política de alivio fiscal culminó en 1686, cuando la Corona redujo a la mitad los cuatro unos por ciento y también decidió suprimir otros dos importantes servicios de millones: los servicios de las carnes y de los tres millones ${ }^{51}$.

Los servicios de las Quiebras, los Tres Millones y las Carnes habían sido transferidos por la Corona a Madrid a cambio de donativos durante las décadas precedentes y en 1670 y 1686 la villa decidió mantener el cobro de tales servicios, que se prolongó durante todo el siglo XVIII, hasta su desaparición en el siglo XIX ${ }^{52}$. Estos servicios se recaudaban a través de gravámenes sobre el vino, la carne y, en menor medida, el aceite y de acuerdo con nuestros cálculos su valor era considerable. Las Quiebras, Tres Millones y las Carnes aportaron a la ciudad el 30\% de sus ingresos fiscales entre 1686 y 1700, y merece la pena recordar que su valor medio anual representó el $21 \%$ del total de los impuestos reales y municipales cobrados en la ciudad en el mismo período. No es sorprendente, por tanto, que la influencia de estos impuestos sobre los precios y salarios reales fuera también destacada. Si las Quiebras, los Tres Millones y las Carnes hubieran desaparecido el nivel de precios se hubiera reducido un 6-7\% en los años 1686-1700 y los salarios reales habrían crecido en las misma proporción ${ }^{53}$.

La conservación por Madrid de las Quiebras después de 1670 y los Tres Millones y las Carnes después de 1686 muestra el significado real del control ejercido por la ciudad sobre las «Sisas Reales». Siguiendo la política de alivio de la carga fiscal adoptada por la Corona desde 1670, Madrid podría haber suprimido las Quiebras, los Tres Millones y las Carnes, lo que hubiera aliviado el peso de la carga fiscal que recaía sobre la ciudad con efectos favorables sobre los precios y salarios. El problema residía en que desde los años 60 la deuda municipal había llegado a ser demasiado grande para las posibilidades financieras de la capital, y esto evitó que las autoridades municipales adoptaran medidas para aligerar el peso de los impuestos municipales. En $1679 \mathrm{Ma}-$ drid debía 17 millones de ducados a sus acreedores y de hecho había renunciado a amortizar las sumas prestadas, limitándose a atender al pago de los intereses de la deuda, que en algunos años absorbió el 83\% de los ingresos municipales. Aunque la ciudad pudo aligerar algo esta carga a través de rebajas en el tipo de interés devengado por la deuda municipal, esto no bastó y la villa decidió conservar el cobro de las «Sisas Reales» y de la mayoría de los

51 SÁNCHEZ BELÉN, 1996 y ANDRÉS UCENDO 30/3 (Roma, 2001): 610-11.

52 ANDRÉS UCENDO, 5 (Madrid, 2006): 47-51.

53 Para una comparación de este sistema con otro país de sisas, Holanda, véase GELABERT, 29 (Alicante, 2003): 7-20. 
impuestos municipales creados durante las décadas anteriores para garantizar el pago de los intereses. Esto provocó la conservación de los impuestos indirectos más rentables de la Hacienda Municipal, que gravaban el consumo del vino, la carne, $\mathrm{y}$ en menor medida el aceite, por lo que la necesidad de atender el pago de los intereses de la deuda municipal contribuyó de un modo indirecto pero importante a los altos niveles de precios y a los bajos salarios reales prevalecientes en la capital castellana.

\section{CONCLUSIONES}

Las páginas precedentes han enfatizado las estrechas relaciones fiscales y financieras entre la Hacienda Real castellana y la hacienda municipal madrileña a lo largo del siglo XVII y también han remarcado hasta qué punto los altos niveles de precios y el descenso de los salarios reales típicos del período fueron debidos a la política fiscal adoptada por las autoridades municipales. Gracias a la concesión de 17 millones de ducados en varios donativos a la Corona, entre 1653 y 1679 Madrid obtuvo la mayor parte de los servicios de millones cobrados por la Corona en la ciudad y su distrito fiscal — «Sisas Reales»— y al mismo tiempo introdujo nuevos y rentables impuestos municipales. Tanto los impuestos municipales como las «Sisas Reales» eran recaudados por las autoridades de la villa a través de impuestos que recaían de forma predominante sobre el consumo del vino y carne, ejerciendo una fuerte influencia sobre los niveles de precios y salarios de la ciudad en el último tercio del siglo. Para evitar estas consecuencias las autoridades urbanas podrían haber seguido una política distinta, introduciendo medidas de alivio de la carga fiscal, al igual que hizo la Corona en las últimas décadas del siglo. Si la ciudad no siguió esta vía se debió al rápido crecimiento de la deuda municipal entre 1653 y 1679. Como se ha señalado en la primera parte, Madrid había recurrido a la movilización de su deuda municipal para obtener los fondos otorgados a la Corona en los donativos del período, y la mayoría de los ingresos fiscales de la capital, tanto los procedentes de las «Sisas Reales» como del resto de los impuestos municipales, se dedicaron al pago de sus intereses a los propietarios de la deuda municipal.

Los deudores castellanos, fueran individuos o corporaciones, gozaban de la facultad de renunciar al pago de los principales prestados a ellos siempre que atendieran el pago de los intereses, por lo que desde un punto de vista práctico la decisión tomada por Madrid de suspender la amortización de los principales de su deuda desde los años 60, concentrándose en el pago de los intereses, significaba que el endeudamiento de la capital se había convertido en permanente. 
La necesidad de atender al pago puntual de los intereses de la deuda municipal obligó a la ciudad a mantener un sistema tributario basado en un grupo de impuestos indirectos sobre el consumo del vino, carnes, aceite y carbón cuya influencia sobre los precios y salarios fue destacada (parte 3). Cuando recordamos que tales tributos recaían sobre los sectores más populares de la población de la villa y que ésta dedicaba la mayor parte de sus ingresos al pago de los intereses de la deuda municipal, entonces es fácil concluir que el sistema fiscal desarrollado por la capital tuvo un claro efecto redistributivo que beneficiaba a los acreedores de la ciudad. Como los regidores y sus parientes tenían un lugar de privilegio en la lista de los acreedores de Madrid, entonces su interés en el mantenimiento de este sistema fiscal a pesar de sus negativos efectos sobre los precios y salarios reales es fácil de comprender.

El análisis realizado en las partes 2 y 3 muestra que la tributación tendió a elevar los niveles de precios alrededor de un 16-20\% en el último tercio del siglo, reduciendo los salarios reales en la misma medida, y también muestra que los impuestos municipales tuvieron una importante responsabilidad en este proceso. Esto confiere credibilidad a las teorías más tradicionales acerca de las consecuencias de la fiscalidad sobre la economía y sociedad castellanas del siglo XVII, enfatizando el relieve de la fiscalidad municipal, tradicionalmente subestimado, y al mismo tiempo plantea la cuestión de averiguar si el caso madrileño puede considerarse representativo de una tendencia general o una excepción causada por las peculiaridades de la capital.

Por un lado, hay razones para sugerir que el caso madrileño bien puede reflejar una situación más general. El mercado de trabajo de la capital ejerció un fuerte atractivo sobre los inmigrantes de otras ciudades castellanas durante todo el siglo a causa de los elevados salarios que se pagaban en la construcción urbana, aunque probablemente la tendencia de los salarios nominales en otras ciudades castellanas como Valladolid debió ser similar a la madrileña ${ }^{54}$. Considerando lo que sabemos acerca de la fiscalidad real y municipal en Valladolid, parece probable que la fiscalidad haya tenido una responsabilidad destacada en esta trayectoria, por lo que el ejercicio realizado en las páginas anteriores podría considerarse, al menos desde este punto de vista, representativo ${ }^{55}$.

54 La evolución de los salarios monetarios plantea también el papel desempeñado por las migraciones en la regulación del mercado de trabajo urbano, que aparentemente mostraba, según Hamilton, una mayor elasticidad a las diferencias de precios que el mismo comercio. Véase HAMILTON, 1975: 284. A través de un sistema de licitación pública, las obras reales podían atraer a los mejores trabajadores del reino, de modo que los salarios de Madrid, el mayor mercado de trabajo sin duda, podían influir en la evolución de los salarios de otras poblaciones urbanas de Castilla. Al respecto es mucho el trabajo de investigación que aún queda por hacer. Véase el caso de Londres respecto a Inglaterra en BOULTON, (Oxford, 1996): 283-287.

55 GUTIÉRREZ ALONSO, 1989: 170-182. 
¿Y qué se puede afirmar acerca de las relaciones entre la fiscalidad, los crecientes niveles de precios y las dificultades de las manufacturas urbanas castellanas, que fue y todavía es uno de los aspectos básicos de la visión tradicional sobre las repercusiones de la fiscalidad castellana? En un mundo mercantilista en donde la necesidad de reducir costes para ganar competitividad era sentida agudamente, el que los niveles de precios hubiesen sido elevados en un $16-20 \%$ por la fiscalidad bien pudo haber constituido una seria desventaja para las industrias urbanas en su competencia con los productos foráneos más baratos, lo que parecería apoyar las argumentaciones de los arbitristas. El problema aquí reside en que Madrid no puede ser considerada como una ciudad industrial, por lo que trabajos sobre las relaciones entre la fiscalidad, los precios y los salarios en las ciudades manufactureras del reino como Toledo, Segovia o Cuenca podrían arrojar nueva luz sobre este asunto esencial. Si los impuestos indirectos hubieran afectado a los niveles de precios y salarios en estas ciudades en la misma forma que en Madrid, esto constituiría una confirmación de la teoría tradicional, que ve en el desarrollo de la fiscalidad indirecta una de las principales causas de las dificultades de las industrias castellanas del período.

\section{BiBLIOGRAFÍA}

Allen, Robert C, "The Great Divergence in European Wages and Prices from the Middle Ages to the First World War”, Explorations in Economic History, 38 (Orlando, 2001): 411-447.

Alvar Ezquerra, Alfredo, El nacimiento de una capital europea: Madrid entre 1561 y 1606, Madrid, Turner/Ayuntamiento de Madrid, 1989.

Andrés Ucendo, José Ignacio, "Castile's Tax Sytem in the Seventeenth Century", The Journal of European Economic History, 30/3 (Roma, 2001): 597-621.

Andrés Ucendo, José Ignacio, "Fiscalidad real y fiscalidad municipal en Castilla durante el siglo XVII: el caso de Madrid”, Investigaciones de Historia Económica, 5 (Madrid, 2006): 41-70.

Andrés Ucendo, José Ignacio, "Government Policies and Development of Financial Markets: The case of Madrid in the Seventeenth Century", en Fausto Piola Caselli (ed.), Government Debts and Financial Markets in Europe, Londres, Pickering and Chatto, 2008; 67-80.

Arriquíbar, Nicolás de, Recreación política. Reflexiones sobre el Amigo de los Hombres en si tratado de población, Vitoria, Tomás de Robles y Navarro, 1779; Edición de Jesús Astigarraga y José Manuel Barrenechea, Bilbao, Instituto Vasco de Estadística, 1987.

Artola, Miguel, La Hacienda del Antiguo Régimen, Madrid, Alianza, 1980. 
Azcárate, J.M., “Instrucción para las construcciones reales en el siglo XVII”, Boletín del Seminario de Estudios sobre Arte y Arqueología, Universidad de Valladolid, 24 (Valladolid, 1960): 223-230.

Bernardos, José Ubaldo, No sólo de pan... Ganadería, abastecimiento y consumo de carne en Madrid (1450-1805), Madrid, UAM, 2008.

Boulton, J., "Wage labour in seventeenth-century London”, Economic History Review, XLIX/2 (Oxford, 1996): 268-290.

Carbajo Isla, M.F., La población de la villa de Madrid. Desde finales del siglo XVI hasta mediados del siglo XIX, Madrid, Siglo XXI, 1987.

Caxa de Leruela, Miguel, Restauración de la abundancia de España, Madrid, Instituto de Estudios Fiscales, 1975 [1631].

Colmeiro, Manuel, Historia de la economía política española, Madrid, Edición de la Biblioteca Regeneracionista, Fundación Banco Exterior, 1986 [1863].

Díaz González, Francisco Javier, La Real Junta de Obras y Bosques en la época de los Austrias, Madrid, Dykinson, 2002.

Domínguez Ortiz, Antonio, Política y Hacienda de Felipe IV, Madrid, Editorial de Derecho Financiero, 1960.

Feliu, Gaspar, Precios y salarios en la Cataluña Moderna, Madrid, Banco de España, 1991.

Feliu, Gaspar, "Los salarios en Europa durante la revolución de los precios: algunas comparaciones”, en Doctor Nadal. La industrializació i el desenvolupament econòmic d'Espanya, Barcelona, Universitat de Barcelona, 1999, vol. 1; 83-94.

Fortea, José Ignacio, Monarquía y Cortes en Castilla. Las ciudades ante la política fiscal de Felipe II, Valladolid, Junta de Castilla y León, 1990.

Fortea Pérez, J.I., “La propiedad de las corporaciones urbanas”, en S. de Dios, J. Infante, R. Robledo y E. Torijano (coords.), Historia de la propiedad en España. Siglos XV-XX, Madrid, 1999.

García Sanz, Ángel, "Repercusiones de la fiscalidad sobre la economía castellana en los siglos XVI y XVII”, Hacienda Pública Española, I (Madrid, 1991): 15-24.

Gelabert, Juan Eloy, La bolsa del rey, Crítica Barcelona, 1997.

Gelabert, Juan Eloy, “La bolsa del rey y la vida de los súbditos, 1550-1650”, Estudis: Revista de Historia Moderna, 29 (Alicante, 2003): 7-20.

Gutiérrez Alonso, Adriano, Estudio sobre la decadencia de Castilla. La ciudad de Valladolid en el siglo XVII, Valladolid, Universidad de Valladolid, 1989.

Hamilton, Earl J., El tesoro americano y la revolución de los precios en España 1501-1650, Barcelona, Ariel, 1975 [1934].

Hamilton, Earl J., Guerra y precios en España 1651-1800, Madrid, Alianza, 1988 [1947].

Hoz García, Carlos de la, "El sistema fiscal de Madrid en el Antiguo Régimen: las sisas”, Anales de Instituto de Estudios Madrileños, XXV (Madrid, 1988): 371386.

Lanza García, Ramón, “Trabajadores y pretendientes. Notas sobre la inmigración a Madrid en el siglo XVII y principios del XVIII”, en Alberto Marcos Martín (ed.), Hacer Historia desde Simancas. Homenaje a José Luis Rodríguez de Diego, Valladolid, Junta de Castilla y León, 2011; 467-490. 
Larquié, C. y Fayard, J., "Hôtels madrilènes et démographie au XVII siècle”, Mélanges de la Casa de Velázquez, 4 (Madrid, 1968): 229-258.

Llopis, Enrique y García Montero, Héctor, Coste la vida y salarios en Madrid, 16801800. DT-AEHE, $n^{\circ}$ 0901, Madrid, 2009.

López García, J.M. (dir.), El impacto de la Corte en Castilla. Madrid y su territorio en la época moderna, Madrid, Siglo XXI, 1998.

Malanima, Paolo, L'economia italiana. Dalla crescita medievale alla crescita contemporanea, Bologna, Il Mulino, 2002.

Marcos Martín, Alberto, España en los siglos XVI, XVII y XVIII. Economía y sociedad, Barcelona, Crítica, 2000.

Martínez Ruiz, José Ignacio, Finanzas municipales y crédito público en la España Moderna. La Hacienda de la ciudad de Sevilla, 1528-1768, Sevilla, Ayuntamiento de Sevilla, 1992.

Moncada, Sancho de, Restauración política de España, Madrid, Instituto de Estudios Fiscales, 1974 [1618].

Nieto Sánchez, J., Artesanos y mercaderes. Una historia social y económica de Madrid (1450-1850), 2008.

Pinto Crespo, Virgilio y Madrazo Madrazo, Santos (dirs.), Atlas histórico de Madrid, Madrid, Caja Madrid/Lunwerg, 1995.

Reher, D.S. y Ballesteros, E., "Precios y salarios en Castilla la Nueva: La construcción de un índice de salarios reales, 1501-1991”, Revista de Historia Económica, XI/1 (Madrid, 1993): 101-151.

Rey Castelao, Ofelia, "Los estudios sobre fiscalidad en la época moderna: ¿fenómeno historiográfico real o aparente?”, Obradoiro de Historia Moderna, 13 (Santiago de Compostela, 2004): 215-252.

Ringrose, David, Madrid y la economía española, 1560-1850, Madrid, Alianza, 1985.

Ruiz Martín, Felipe, "Procedimientos crediticios para la recaudación de los tributos fiscales en las ciudades castellanas durante los siglos XVI y XVII en las ciudades castellanas: el caso de Valladolid”, en A. Otazu (ed.), Dinero y Crédito. Primer Coloquio Internacional de Historia Económica, Moneda y Crédito, Madrid, 1978; 37-47.

Sánchez Belén, Juan Antonio, La política fiscal en Castilla durante el reinado de Carlos II, Madrid, Siglo XXI, 1996.

Sureda Carrión, José Luis, La hacienda castellana y los economistas del siglo XVII, Madrid, Instituto de Economía Sancho de Moncada, 1949.

Thrupp, Sylvia L., "La industria medieval, 1000-1500”, en C. M. Cipolla (ed.), Historia Económica de Europa (1). La Edad Media, Ariel, Barcelona, 1979; 235294.

Tovar Martín, Virginia, Arquitectura madrileña del s. XVII (datos para su estudio), Madrid, Instituto de Estudios Madrileños, 1983.

Uztáriz, Gerónimo de, Teoría y práctica de comercio y de marina, Madrid, Aguilar, 1968 [1724]. 
Van Zanden, Jan Luiten, "What Happened to the Standard of Living Before the Industrial Revolution? New Evidence from the Western part of the Netherlands", en R. C. Allen, T. Bengtsson y M. Dribe, Living Standards in the Past. New Perspectives on Well-Being in Asia and Europe, Oxford, 2005; 173-194.

Vries, Jan de, La urbanización de Europa, Barcelona, Crítica, 1984.

Wrigley, E.A., Poverty, Progress and Population, Cambridge University Press, 2004.

Yun, Bartolomé, "Las raíces del atraso económico español: crisis y decadencia (1590-1714)”, en F. Comín, M. Hernández y E. Llopis (eds.), Historia económica de España, siglos $X-X X$, Barcelona, Crítica, 2002; 85-120.

Recibido: 21-11-2010

Aceptado: 01-07-2011 
